\title{
Operative Treatment of Spontaneous Pneumothorax and Persistent Air Leaks - The Thoracoscopic Approach
}

\author{
Thapa $B^{1 *}$ \\ ${ }^{\prime}$ Manmohan Cardio-thoracic Vascular and Transplant Center, Institute of Medicine, Tribhuvan University, Nepal
}

*Corresponding Author:

Bibhusal Thapa, Institute of Medicine,

Maharajgunj, Kathmandu, Nepal

Email: thapabibhusal@yahoo.com

\section{Citation}

Thapa B. Operative Treatment of Spontaneous Pneumothorax and Persistent Air Leaks - The Thoracoscopic Approach. Nepal Journal of Medical Sciences. 2014;3(1):14-18.

\begin{abstract}
Background: Spontaneous pneumothoraces are common thoracic surgical problems and when complicated by recurrences and persistent air leaks are often difficult to treat. While conservative non-operative methods were favored in the past, thoracoscopy has made operative treatment more successful, easier and less painful. We reviewed our experience with thoracoscopic management of spontaneous pneumothorax.
\end{abstract}

Methods: We analyzed the retrospective data from the patients who received Video-Assisted Thoracoscopic Surgery for spontaneous pneumothoraces from January 2012 to January 2013 at Manmohan Cardio-thoracic Vascular and Transplant Center.

Results: The male to female ratio was 6:1 with mean age 33 years (minimum 17 years to maximum70 years). The ratio of primary spontaneous to secondary spontaneous was 5:2. Seventeen of 21 patients had air leaks at operation. Seven of 15 patients with primary spontaneous and 4/6 with secondary spontaneous had prior two or more episodes of pneumothorax. Blebs/ bullae were found in 18/21 patients. In 9/18 patients, the bullae/ blebs were stapled while in seven, they were plicated. Only pleurodesis was done in the remaining patients. Additional procedures in the form of decortications were required in three. The chest tube was removed by the second post operative day in 13/21 patients. Prolonged chest tube was required in three patients (persistent leak in two and collection in one patient). One patient needed a subsequent thoracotomy and decortication.

Conclusion: Thoracoscopic approach to spontaneous pneumothoraces and persistent air leaks is feasible and safe. Plication of bullae/ blebs can be a viable alternative when stapling devices are not available.

Keywords: Persistent air leak; pneumothorax; video assisted thoracoscopic surgery

\section{Background:}

Spontaneous pneumothoraces are common thoracic surgical problems. They are not infrequently complicated by recurrences and subsequent infections. Primary spontaneous pneumothoraces(PSP) occur in young individuals with thin tall body habitus due to rupture of sub-pleural blebs in otherwise normal lungs. Secondary spontaneous pneumothoraces(SSP) however occur in older individuals who have diseased lungs with bullae. Aspiration and tube thoracostomy are considered the first line of therapy but are 
known for high rates of recurrence. ${ }^{1}$

Operative intervention in the form of thoracotomy with blebectomy/bullectomy and pleurodesis has been known to have high efficacy in preventing recurrences. They however are often associated with possibility of long term postthoracotomy pain. ${ }^{2-4}$ Since the first report of Video-Assisted Thoracoscopic Surgery (VATS) by Levi et $\mathrm{al}^{5}$ in1991, this minimally invasive technique which has the potential to reduce immediate and long term post-operative pain and to reduce post-op recovery time has taken precedence over open formal thoracotomy in many Thoracic procedures. The comparison of thoracotomy to VATS in the treatment of recurrent pneumothoracesin numerous studies has shown consistently better pain outcomes and overall patient satisfaction with VATS. ${ }^{6-8}$

Thoracotomy has been the method of choice in dealing with recurrent pneumothoraces and pneumothoraces with persistent air leaks (PAL) in our institution when conservative treatment fails. With the recent introduction of the VATS services, these problems are now being tackled via this approach. In this study we reviewed and report our initial experience with thoracoscopic treatment of recurrent pneumothorax and PAL of primary and secondary onset.

\section{Methods:}

The retrospective observational study was conducted from the thoracic surgery database of the Thoracic Surgery unit of Manmohan Cardio-Thoracic Vascular and Transplant Center. Patients who presented to the center with recurrent pneumothorax or PAL of either primary or secondary spontaneous onset were studied. Patients deemed unfit for surgery were excluded.

Patients were initially put on conservative management with suction on the chest tube with $-20 \mathrm{~cm}$ of $\mathrm{H}_{2} \mathrm{O}$ pressure. Autologous blood patching (ABP) in an attempt to seal air leak was employed as a part of conservative management in all patients with SSP. ABP was tried in addition to conservative management in patients with SSP because they were more likely to have co-morbidities and therefore likely to be of greater operative risks. Operative treatment was considered when patient had history of $\geq$ two recurrences or PAL $\geq$ two days duration or when cases of SSP failed three attempts of ABP. The approach was through three port VATS. After noting the findings, the incriminated blebs/ bullae were dealt with. In the initial phase of our experience, when endoscopic staplers were not readily available the blebs/ bullae were plicated using 1-0 polypropylene sutures.
When endoscopic staplers became routinely available, they were stapled using appropriate sized loads. After confirming the absence of major leak and adequate lung expansion, mechanical pleurodesis was done by scraping the parietal pleura using scratch pads mounted on endoscopic graspers. This mechanical pleurodesis was augmented by uniform instillation of $5 \%$ povidone iodine solution on the visceral surface. Post-operatively the chest tube was placed under continuous suction. Chest tube was removed after 48 hrs or when there was no air leak and the drainage from the tube was $\leq 100 \mathrm{ml} / 24 \mathrm{hrs}$ whichever came later. Postoperative analgesia was with parentral analgesia replaced by oral analgesics on $1^{\text {st }}$ post-operative day. Thoracic epidural analgesia was not routinely used. After discharge, the patient was followed up with repeat Chest X-rays at 1 week, 1 month, 3 months and 1 year. Demographic data, operative details (approach, operative findings, method of dealing with the bleb/bulla and type of pleurodesis) and post-operative outcomes in terms of success of sealing of air leak, number of days of post-op leak, post-op tube drainage and recurrence were recorded and studied.

Comparisons were made using chi square test. $\mathrm{P}<0.05$ was considered significant. Data are expressed as means and ranges.

\section{Results:}

Between January 2012 and January 2013, twenty one patients underwent VATS for spontaneous pneumothorax. There were 15 cases of primary spontaneous onset as opposed to six of secondary spontaneous onset. The age ranged from 17 to 70 years and the average age of patients with PSP was $24.9 \pm 8.1 \mathrm{yrs}$ and SSP was $55 \pm 9.2 \mathrm{yrs}$. Male to female ratio was $6: 1$. Majority $(15 / 21)$ of patients had come from outside Kathmandu. Right to Left ratio was 15:6. While all patients with SSP were/had been smokers, 10/15 among PSP cases were not smokers. Two patients, one in each group had history of pulmonary tuberculosis. All but one case of SSP and 12/15 cases of PSP had PAL of various grades immediately pre-operatively. The average duration of air leak prior to VATS was 11 (2-25) days. This duration was slightly longer among SSP (mean- 13.3days) vs. PSP (mean- 10days). There was history of prior episode of pneumothorax in 11 patients (PSP-7, SSP-4). The average number of recurrences among patients with PSP was 1.2 whereas it was 1.5 among those with SSP. History of two or more recurrences was the sole indication in four patients while the presence of PAL despite no history of previous pneumothoraces was the indication in 10 patients. The rest 
seven patients had history of prior episodes along with persistent air leak. A comparative analysis of patients with PSP and SSP is presented in table 1.

Table 1: Comparative analysis of PSP and SSP patients

\begin{tabular}{|c|c|c|c|}
\hline Particulars & $\begin{array}{c}\text { PSP } \\
(n=15)\end{array}$ & $\begin{array}{c}\text { SSP } \\
(n=6)\end{array}$ & $\begin{array}{c}\text { p- } \\
\text { value }\end{array}$ \\
\hline $\begin{array}{l}\text { Persistent air leak at } \\
\text { operation }\end{array}$ & $12(80 \%)$ & $5(83.3 \%)$ & 0.6842 \\
\hline $\begin{array}{l}\text { History of } \geq 2 \\
\text { recurrences }\end{array}$ & $7(46.6 \%)$ & $4(66.6 \%)$ & 0.3673 \\
\hline $\begin{array}{l}\text { Mean number of } \\
\text { days on tube chest } \\
\text { before VATS }\end{array}$ & $\begin{array}{l}9.8 \pm 6.8 \\
\text { days }\end{array}$ & $\begin{array}{l}11.6 \pm 6.5 \\
\text { days }\end{array}$ & 0.9539 \\
\hline $\begin{array}{l}\text { Bullae(SSP) or } \\
\text { bleb(PSP) was } \\
\text { present in }\end{array}$ & $12(80 \%)$ & $5(83.3 \%)$ & 0.6842 \\
\hline $\begin{array}{l}\text { Average no of days } \\
\text { on tube post op }\end{array}$ & $\begin{array}{l}3.0 \pm 2.1 \\
\text { days }\end{array}$ & $\begin{array}{c}3.5 \pm 2.3 \\
\text { days }\end{array}$ & 0.7293 \\
\hline Post op airleak & $1(6 \%)$ & $1(16 \%)$ & 0.5000 \\
\hline $\begin{array}{l}\text { Postoperative } \\
\text { collection }\end{array}$ & $1(6 \%)$ & 0 & 0.7143 \\
\hline $\begin{array}{l}\text { Lung } \\
\text { collapse(partial) }\end{array}$ & $1(6 \%)$ & 0 & 0.7143 \\
\hline Re-intervention & $1(6 \%)$ & 0 & 0.7143 \\
\hline $\begin{array}{l}\text { Full expansion at } 1 \\
\text { week }\end{array}$ & $11(73.3 \%)$ & $5(83.3 \%)$ & 0.5501 \\
\hline $\begin{array}{l}\text { Full expansion at } 3 \\
\text { months }\end{array}$ & $14(93.3 \%)$ & 6 & 0.7143 \\
\hline
\end{tabular}

All patients were operated through VATS approach. Subpleural blebs were found in 11/15 patients with PSP. All these blebs were found in the apices of the upper lobes. Four patients did not have any visible blebs/bullae. In two patients the lung was covered by thick cortex which needed decortications. All but one patient with SSP had bullae. During the initial part of our experience when endoscopic stapling devices were not available to us and also when the patient was not able to afford the device, we plicated the bleb/ bulla using no 1 polypropylene in six patients with PSP and one with SSP. Endoscopic staplers were used in five patients with PSP and four with SSP. This was routinely followed by mechanical pleurodesis with scratch pads and chemical pleurodesis with povidone iodine solution in all patients. A comparison of results in patients who underwent stapling versus those in whom the bullae were plicated is presented in table 2. Four patients with PSP and one with SSP in whom no blebs/ bullae were found had only mechanical and chemical pleurodesis.

Table 2: Comparison of Stapling versus plication of bleb/ bullae.

\begin{tabular}{lccc}
\hline & $\begin{array}{c}\text { Plication } \\
(\mathbf{n}=7)\end{array}$ & $\begin{array}{c}\text { Stapling } \\
(\mathbf{n}=9)\end{array}$ & $\begin{array}{c}\mathbf{p}- \\
\text { value }\end{array}$ \\
\hline PSP & 6 & 5 & \\
SSP & 1 & 4 & 0.2308 \\
$\begin{array}{l}\text { Average duration of } \\
\text { chest }\end{array}$ & $\begin{array}{c}2.2 \pm 0.4 \\
\text { days }\end{array}$ & $\begin{array}{c}3.1 \pm 2.6 \\
\text { days }\end{array}$ & 0.4278 \\
$\begin{array}{l}\text { Postoperative air leak } \\
\begin{array}{l}\text { Postoperative } \\
\text { collection }\end{array}\end{array}$ & 0 & 1 & 0.5625 \\
\hline
\end{tabular}

The chest tube was removed on the $2^{\text {nd }}$ POD in 13 and on $3^{\text {rd }}$ POD in five patients. One patient in each in group had chest tube for 10 days each due to persistent air leak. One such patient from PSP group neededthoracotomy and closure of BPF. There was no post-operative pleural infection and no peri-operative mortality.

Two patients reached a follow up period of 1 year, 12 patients reached 6 months and six have reached 3 months. No recurrences have been encountered during this period.

\section{Discussion:}

Spontaneous pneumothorax has traditionally been managed by conservative treatment including observation and tube thoracostomy. Only in cases of prolonged air leakage and recurrence was a surgical procedure considered. Surgical approach invariably included thoracotomy. Until the recent addition of VATS services at our institution, this was the accepted approach. Since the initiation of VATS, the treatment of primary spontaneous pneumothorax has changed dramatically world-wide. ${ }^{1}$ Many investigators have since reported extensively about the usefulness and safety. ${ }^{9-12}$

With the introduction of VATS, there has been a change in our practice. Since Jan 2012 VATS approach has been used routinely in our institution to deal with spontaneous pneumothoraces and PAL. Although this study represents our very early experience with this procedure, the fact that we were able to attain a successful outcome in 20/21 patients demonstrates its efficacy. This technique was applied to 
both cases of PSP and SSP in our series and although the number of cases in SSP group was small, the success rates were uniformly good with only one patient in each group requiring prolonged chest tube drainage ( $>7$ days) in each group. In the present series we included and operated upon only patients who either had history of $\geq$ two recurrences or PAL $\geq$ two days duration or failed three attempts of PAL. However increasing evidence seems to suggest that it may be justified even in first episode of pneumothorax. ${ }^{1}$

In one patient with SSP and six with PSP, we had to plicate the bulla/ bleb as the endoscopic stapling device was either not available or not within the patient's means. Despite this, the success rates and number of days with chest tube were very similar. This technique of plication/ligation of bullae has been described in literature with equally good results. ${ }^{2,14}$ This holds special significance in our context where not all patients will be able to afford stapling devices.

VATS has been reported to be associated with a higher recurrence than open thoracotomy ${ }^{13}$ Sawada et al $^{1}$ found in their series of 281 patients that the overall recurrence rates of conservative treatment was $56.4 \%$, open thoracotomy $3.0 \%$, and VATS $11.7 \%$. There was no statistical difference between thoracotomy and VATS $(p=0.15)$. This slightly higher rate of recurrence is however offset by the better outcomes in terms of lesser pain and more acceptable cosmesis offered by VATS. ${ }^{1}$ In our series, we haven't come across any recurrence. This is more likely to be due to the small number of cases and short follow up.

The complication rates with VATS has been low in our series with 2 patients requiring prolonged chest tube drainage (>Seven days) and one requiring aspiration of pleural fluid post-operatively(14\%). This is comparable to what is reported in literature. ${ }^{1,2,4}$

This study represents our very early experience of using VATS for treatment and prevention of recurrences of spontaneous pneumothoraces. The numbers are small and we have not compared results with that of thoracotomy and bullectomy. A larger study will be needed to truly objectively quantify the results, feasibility and complication rates of this procedure in our setting.

\section{Conclusion:}

VATS has been well accepted as the procedure of choice in the treatment of spontaneous pneumothoraces. The experience with this procedure in our center is limited but the results have been encouraging. Plication can be considered a viable option when stapling devices are not available.

\section{Acknowledgements:}

The author wishes to acknowledge the constant help and support provided by Prof. Prakash Sayami and also the help received from colleagues (Drs Ranjan and Kajan) in data collection and patient follow up.

\section{Conflict of interest: none}

\section{Funding: none}

\section{References:}

1) Sawada S, Watanabe $Y$, Moriyama S. Video-Assisted Thoracoscopic Surgery for Primary spontaneous pneumothorax. Chest 2005;127:2226-30. http://dx.doi.org/10.1378/chest.127.6.2226

2) Mouroux J, Elkaim D, Padovani B. Video-assisted thoracoscopic treatment of spontaneous pneumothorax: technique and results of one hundred cases. J ThoracCardiovascSurg 1996;112:385-91. http://dx.doi.org/10.1016/S0022-5223(96)70266-0

3) Waller D, Forty J, Morritt G. Video-assisted thoracoscopic surgery versus thoracotomy for spontaneous pneumothorax. Ann ThoracSurg 1994;58:372-6.

http://dx.doi.org/10.1016/0003-4975(94)92210-1

4) Liu HP, Lin PJ, Hsieh MJ. Thoracoscopic surgery as a routine procedure for spontaneous pneumothorax: results from 82 patients. Chest 1995;107:559-62. http://dx.doi.org/10.1378/chest.107.2.559

5) Levi JF, Kleinmann P, Riquet M. Percutaneous parietal pleurectomy for recurrent spontaneous pneumothorax. Lancet1990;336:1577-8. http://dx.doi.org/10.1016/0140-6736(90)93351-O

6) Kim $\mathrm{KH}$, Kim HK, Han JY, et al Transaxillaryminithoracotomy versus video-assisted thoracic surgery for spontaneous pneumothorax. Ann ThoracSurg1996;61:1510-2. http://dx.doi.org/10.1016/0003-4975(96)00113-0

7) Hyland MJ, Ashrafi AS, Crepeau A, et al. Is videoassistedthoracoscopic surgery superior to limited axillary thoracotomyin the management of spontaneous pneumothorax? CanRespir J 2001;8:339-43.

8) Bertrand PC, Regnard JF, Spaggiari L. Immediate, 
long term results after surgical treatment of primary spontaneous pneumothorax by VATS. Ann ThoracSurg 1996;61:1641-4.

http://dx.doi.org/10.1016/0003-4975(96)00190-7

9) Stammberger U, Steinacher C, Hillinger S. Early and long-term complaints following video-assisted thoracoscopic surgery: evaluation in 173 patients. Eur J CardiothoracSurg2000;18:7-11.

http://dx.doi.org/10.1016/S1010-7940(00)00426-7

10) Margolis M, Gharagozloo F, Tempesta B. Videoassisted thoracic surgical treatment of initial spontaneous pneumothorax in young patients. Ann ThoracSurg2003;76:1661-4.

http://dx.doi.org/10.1016/S0003-4975(02)04816-6

11) Cardillo G, Facciolo F, Regal M. Recurrences following videothoracoscopic treatment of primary spontaneous pneumothorax: the role of redo-videothoracoscopy.Eur J CardiothoracSurg 2001;19:396-9.

http://dx.doi.org/10.1016/S0003-4975(02)04816-6

12) Massard G, Thomas P, Wihlm J-M. Minimally invasive management for first and recurrent pneumothorax. Ann ThoracSurg1998;66:592-9.

http://dx.doi.org/10.1016/S0003-4975(98)00621-3

13) Cole FH, Jr, Cole FH, Khandekar A. Video-assisted thoracic surgery: primary therapy for spontaneous pneumothorax? Ann ThoracSurg1995;60:931-3. http://dx.doi.org/10.1016/0003-4975(95)00598-F

14) NathansonLK,ShimiSM, WoodRA.Videothoracoscopic ligation of bulla and pleurectomy for spontaneous pneumothorax. Ann ThoracSurg1991;52:316-9. http://dx.doi.org/10.1016/0003-4975(91)91366-4 